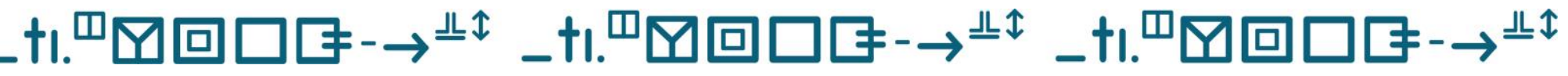

\title{
Os cantos dos Aedos em novas sensorialidades e "O direito à literatura": uma adaptação da Odisseia para leitura de alunos surdos
}

\section{The chaints of Aoidos in new sensorialities and "the right to literature": an daption of the Odyssey for the reading of deaf students}

\footnotetext{
(iD) Sueli Maria de Oliveira Regino

Universidade Federal de Goiás, Goiânia, Goiás, Brasil sueli regino@ufg.br

Resumo: Este trabalho expõe algumas das dificuldades apresentadas por alunos surdos do Curso de Letras: Libras Universidade Federal de Goiás (UFG), Goiânia, para a leitura de textos literários e teóricos nas disciplinas relacionadas aos Estudos Literários. Defende a importância da Literatura para a formação desses alunos e apresenta as ações que antecederam a adaptação do poema Odisseia de Homero para ser narrado, gravado em áudio e interpretado em libras, visando a produção de uma série de interprogramas para a TV UFG. O principal objetivo desse projeto de adaptação da Odisseia para o português e sua subsequente tradução para a libras foi atender os alunos surdos que frequentam o curso de Letras: Libras na UFG, colocando ao seu alcance, em sua 


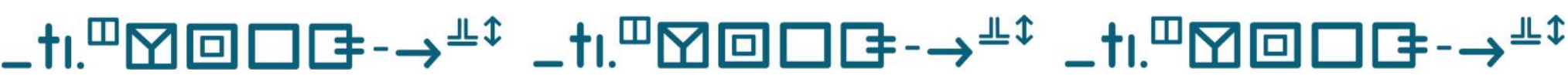

Os cantos dos Aedos em novas sensoriades e "O direito à literatura": uma adaptação da Odisseia para leitura de alunos surdos

Sueli Maria de Oliveira Regino · Goiamérico Felício Carneiro dos Santos

língua natural, um dos textos fundadores da cultura ocidental.

Palavras-chave: Odisseia. Adaptação literária. Leitura de alunos surdos.

Abstract: This work exposes some of the difficulties presented by deaf students of the Letras: Libras Course at the Universidade Federal de Goiás (UFG) in Goiânia, Brazil, when reading literary and theoretical texts in disciplines related to Literary Studies. It defends the importance of Literature for the training of these students, and presents the actions that preceded the adaptation of Homer's poem, Odyssey, to be narrated, recorded in audio, and interpreted in Libras, aiming at the production of a series of interprograms for TV UFG. The main goal of this project of adaption of the Odyssey to Portuguese and its subsequent translation into Libras, was to assist the deaf students who attend the Letras: Libras course at the UFG, and to offer them, in their natural language, one of the founding texts of Western culture.

Keywords: Odyssey. Literary adaptation. Reading of deaf students.

Submetido em 20 de abril de 2021. Aceito em 04 de outubro de 2021. Publicado em 10 de novembro de 2021. 


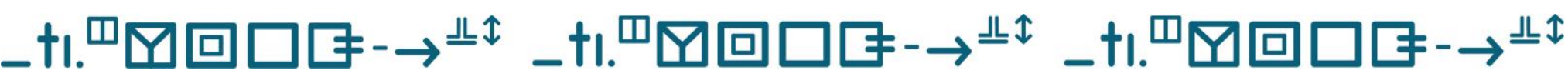

Os cantos dos Aedos em novas sensoriades e "O direito à literatura": uma adaptação da Odisseia para leitura de alunos surdos

Sueli Maria de Oliveira Regino · Goiamérico Felício Carneiro dos Santos

\section{Introdução}

Traduções e adaptações literárias são realizadas desde a Antiguidade Clássica, quando textos de poetas gregos eram vertidos para o latim. A primeira tradução latina de uma obra literária grega aconteceu por volta de 250 a. C., com a tradução do poema homérico Odisseia para a língua latina, realizada por Lívio Andrônico. Nos scriptoria dos mosteiros medievais, além das cópias dos textos latinos, eram frequentes os trabalhos de adaptação e reescrita de obras clássicas, realizadas sem grandes preocupações com a forma original. Ainda não havia sido consolidado o conceito de "autoria" e considerava-se uma espécie de virtude a "melhoria" dos textos produzidos pelas gerações anteriores.

Desde o século XIII, nos mosteiros, hagiografias eram traduzidas e adaptadas para o público religioso. A partir do século XVI, adaptações realizadas para o teatro se tornaram comuns, como a tragédia Romeu e Julieta de Shakespeare, que teve como fonte um conto italiano. No século XVII, Charles Perrault fez as primeiras adaptações de contos tradicionais para crianças. As adaptações de textos clássicos para o público jovem intensificaram-se a partir do século XVIII, com as compilações dos Irmãos Grimm, de Aleksandr Afanasev e de Hans Cristian Andersen. A partir desse breve histórico, é possível observar que as adaptações sempre foram elaboradas em função do público ao qual se destinavam. Hoje, é possível afirmar que a função mais importante das 


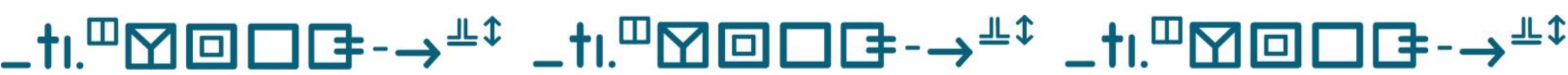

Os cantos dos Aedos em novas sensoriades e "O direito à literatura": uma adaptação da Odisseia para leitura de alunos surdos

Sueli Maria de Oliveira Regino · Goiamérico Felício Carneiro dos Santos

adaptações tem sido introduzir o público de leitores inexperientes ao universo da literatura.

Este artigo, que trata da adaptação da obra Odisseia, em língua portuguesa, escrita em forma de roteiro para um interprograma na TVUFG, tem como objetivo expor os antecedentes do projeto "A Odisséia de Homero: roteiro bilíngue (português/libras) para a série televisiva Hora do Conto" (2019) ', assim como apresentar algumas peculiaridades do processo de adaptação desse poema épico milenar de Homero. No decorrer deste trabalho, buscou-se expor as dificuldades observadas na leitura de textos literários e teóricos das disciplinas relacionadas aos Estudos Literários no Curso de Letras: Libras da Universidade Federal de Goiás (UFG), Goiânia, defendendo a importância do estudo da Literatura para a formação de alunos surdos e ouvintes. Esse projeto de adaptação literária dos cantos da Odisseia em português e libras visa, principalmente, atender os alunos surdos que frequentam o curso de Letra: Libras na UFG, colocando ao seu alcance, em sua língua natural, um dos textos fundadores da cultura ocidental.

No Brasil, o trabalho de adaptação literária, geralmente realizado por escritores nos intervalos de seu processo de criação, foi responsável pela popularização de textos clássicos e pela formação de um público leitor. Um bom exemplo são as obras traduzidas por Monteiro Lobato, que Bottmann (2011), ao levantar a extensa relação de títulos traduzidos pelo escritor, aponta as obras destinadas a 


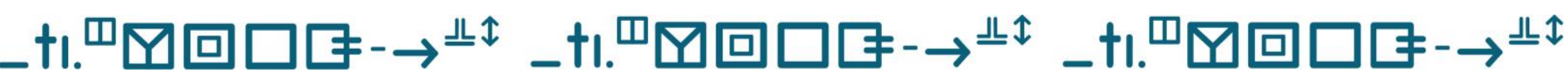

Os cantos dos Aedos em novas sensoriades e "O direito à literatura": uma adaptação da Odisseia para leitura de alunos surdos

Sueli Maria de Oliveira Regino · Goiamérico Felício Carneiro dos Santos

crianças e jovens: Alice no país das Maravilhas e Alice no país dos Espelhos de Lewis Carroll; Peter Pan de James Barrie; Dom Quixote de La Mancha, de Cervantes; Robinson Crusoe, de Daniel Defoe; Mowgli, o menino-lobo, de Rudyard Kipling; Pollyanna e Pollyanna moça, de Eleonor Porter; os primeiros livros da série Tarzan, de Edgar Rice Burroughs, além de alguns contos das Mil e uma noites, obra anônima de tradição árabe; contos de Hans Cristian Andersen, dos Irmãos Grimm e de Charles Perrault.

Para Lobato, traduzir era "abrir janelas para o mundo" (BOTTMANN, 2011) e seu trabalho de adaptação literária para jovens abriu, certamente, amplas e ensolaradas janelas para as gerações que conheceram e admiraram o seu extraordinário trabalho de criar, editar e divulgar literatura. Foi sob a inspiração desse espírito lobatiano que os primeiros projetos de adaptar textos literários para a libras, tornandoos mais acessíveis aos surdos, surgiram entre os professores do curso de Letras: Libras da UFG.

$\mathrm{Na}$ primeira seção deste artigo, pretende-se expor a natureza dos problemas que levaram à elaboração de projetos de tradução e adaptação de obras literárias para atender os alunos surdos do Curso de Letras: Libras da UFG; relatar algumas das estratégias aplicadas para estimular a leitura de textos literários e teóricos nas disciplinas relacionadas aos Estudos Literários, e pontuar a importância da Odisseia para a formação de jovens leitores. Na segunda seção, aborda-se o tema das funções da literatura, 


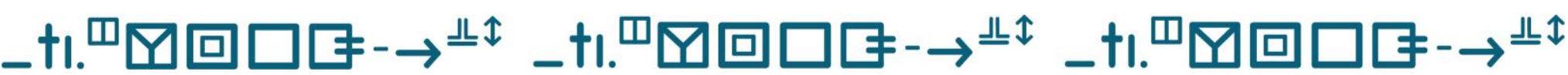

Os cantos dos Aedos em novas sensoriades e "O direito à literatura": uma adaptação da Odisseia para leitura de alunos surdos

Sueli Maria de Oliveira Regino · Goiamérico Felício Carneiro dos Santos

procurando confirmar a importância da arte literária, não apenas para o desenvolvimento cognitivo e intelectual desses alunos, como também para sua formação ética e humanística. Na terceira seção, são apresentados alguns dos procedimentos utilizados no decorrer do trabalho de adaptação da Odisseia de Homero, reescrita em forma de roteiro de leitura para um interprograma bilíngue (português/libras) da TV UFG.

O projeto de um seriado bilíngue, em português e libras, que apresentasse a Odisseia no formato de um interprograma, é resultado de uma parceria entre a Faculdade de Letras (UFG), a Pós-Graduação da Faculdade de Informação e Comunicação (UFG) e a Fundação RTVE -TVUFG, atendendo ao objetivo de promover a leitura em libras de um dos textos nucleares da cultura ocidental. Dessa forma, a Odisseia de Homero alcançará escolas e comunidades surdas de nosso país.

\section{A leitura de textos literários e teóricos}

O primeiro curso presencial de Letras: Libras no Brasil teve início em 2009, em horário noturno, na Faculdade de Letras da Universidade Federal de Goiás. Na grade curricular do curso recém-criado predominavam disciplinas da área de Linguística, com apenas três disciplinas voltadas aos estudos literários: Introdução aos Estudos Literários, apresentada aos alunos do primeiro semestre; Tópicos da História da Literatura, no segundo semestre, e Literatura Surda, no quarto semestre. 


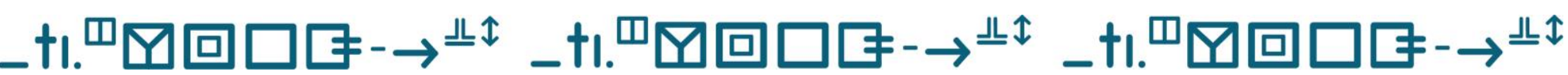

Os cantos dos Aedos em novas sensoriades e "O direito à literatura": uma adaptação da Odisseia para leitura de alunos surdos

Sueli Maria de Oliveira Regino · Goiamérico Felício Carneiro dos Santos

Dessas três disciplinas, somente Literatura Surda era específica do curso de Letras: Libras. As duas primeiras disciplinas de Literatura, elaboradas para atender às necessidades do novo curso de Letras: Libras, mantiveram os títulos e as ementas das duas disciplinas de iniciação literária que compunham a grade dos outros cursos da Faculdade de Letras da UFG.

A ementa da disciplina Introdução aos Estudos Literários tem como foco: apresentar alguns dos conceitos fundamentais dos estudos da literatura e a abordagem da problemática dos gêneros literários, com noções gerais sobre a narrativa, o drama e o poema, enquanto a disciplina Tópicos da História da Literatura concentra-se nos fenômenos relativos aos períodos literários e suas conexões com os diferentes contextos histórico-culturais.

Em turmas compostas por alunos surdos e ouvintes, não é difícil imaginar a extensão dos desafios relativos à aplicação de uma ementa que exige, da parte dos alunos, disposição e competência linguística para leituras mais extensas, como os poemas homéricos, e para a compreensão de conceitos teóricos básicos como "mimesis" e "verossimilhança", expostos por Aristóteles (2011) na Poética. O fato de os alunos surdos terem o português como segunda língua, chegando, muitas vezes, à universidade sem o domínio da leitura e da escrita em língua portuguesa, tem sido um considerável obstáculo à leitura de textos literários e teóricos. 


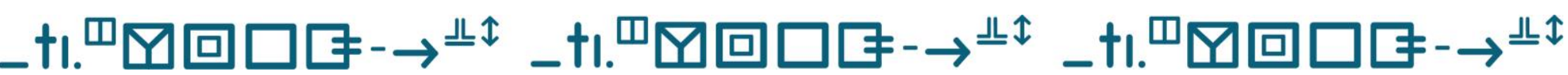

Os cantos dos Aedos em novas sensoriades e "O direito à literatura": uma adaptação da Odisseia para leitura de alunos surdos

Sueli Maria de Oliveira Regino · Goiamérico Felício Carneiro dos Santos

Embora a leitura dos poemas homéricos seja um marco inicial para o estudo do imenso acervo de narrativas da literatura ocidental, o que se tem constatado nas avaliações, ano após ano, é o número mínimo de alunos, surdos e ouvintes, que realmente realiza a leitura desses textos. Diante desse fato, decidiu-se oferecer, ao lado das indicações bibliográficas tradicionais, uma adaptação para crianças e jovens, escrita por Ruth Rocha, e uma versão em quadrinhos dos poemas homéricos, como opção de leitura da Odisseia. Verificou-se que, apesar dessas facilidades, impensáveis em outro contexto, boa parte dos alunos não completava a leitura dos textos literários adaptados, especialmente os alunos surdos.

A constatação das dificuldades dos alunos, surdos e ouvintes, com a leitura de textos literários e teóricos nas disciplinas relacionadas aos Estudos Literários levou à adoção de novos recursos. Um deles consistiu na exibição em sala de aula de filmes baseados nas obras literárias que deveriam ser lidas no semestre. Outro recurso foi a apresentação, em forma de slides, de cada um dos cantos da Odisseia, ilustrados por imagens de vasos gregos, pinturas, esculturas do Renascimento e do Romantismo, representando cenas homéricas. Observou-se, no entanto, que as dificuldades dos alunos com a compreensão do plano geral da obra persistiam. No caso da Odisseia, cenas como o confronto entre Odisseu e o ciclope Polifemo, a chegada ao Hades ou o massacre dos pretendentes eram reproduzidas 


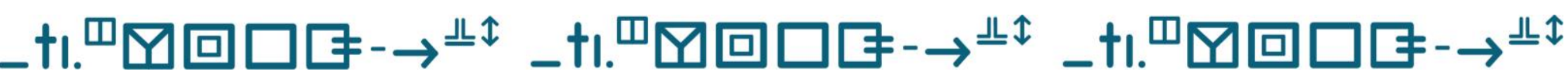

Os cantos dos Aedos em novas sensoriades e "O direito à literatura": uma adaptação da Odisseia para leitura de alunos surdos

Sueli Maria de Oliveira Regino · Goiamérico Felício Carneiro dos Santos

em língua de sinais, a partir da observação visual das imagens fílmicas, mas desconectadas dos episódios restantes. O reconhecimento da obra como um todo, com início, desenvolvimento de ações interligadas e finalização dos eventos, parecia estar aquém das possibilidades de apreensão de alguns dos alunos, surdos e ouvintes, que apresentavam grande dificuldade em leitura e compreensão textual.

Em geral, adultos que não conseguem compreender o que leem também acham difícil recontar uma história que acabaram de ouvir ou de ler. Isso também acontece com textos fílmicos, pois quando solicitados a relatar, de forma geral, um vídeo assistido em sala de aula, respondem por meio da narração episódica de uma ou outra cena e nem todos conseguem apresentar um resumo satisfatório do enredo. Normalmente, o histórico de leitura desses alunos durante a infância é semelhante: em casa, entre familiares, tiveram pouco acesso à narrativas orais e escritas. Para muitos, os primeiros contatos com a leitura de textos narrativos ocorreram na escola, de forma nem sempre favorável e eficaz.

No caso da criança surda, filha de pais ouvintes que desconhecem a língua de sinais, a situação costuma ser ainda mais difícil. Um surdo submetido a essa condição familiar atravessa os primeiros anos da infância sem ter qualquer contato com o cancioneiro infantil, que reúne cantigas de ninar e de roda, ou narrativas da tradição, como as orações, 


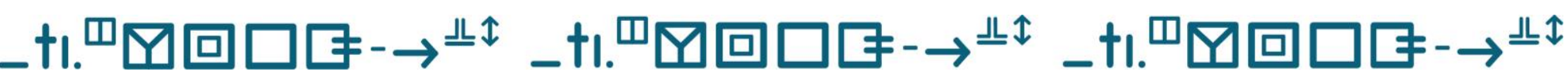

Os cantos dos Aedos em novas sensoriades e "O direito à literatura": uma adaptação da Odisseia para leitura de alunos surdos

Sueli Maria de Oliveira Regino · Goiamérico Felício Carneiro dos Santos

parlendas, quadrinhas e adivinhas. O fluxo de palavras que movimenta a roda do intelecto é estancado pela surdez. Sem o acesso à língua de sinais, língua natural do surdo, a surdez torna-se uma barreira para o compartilhamento das histórias contadas em família e para a plena compreensão das narrativas apresentadas nos programas infantis da tevê. Sem o uso precoce da língua de sinais, o acesso a qualquer narrativa só ocorre quando o surdo aprende, geralmente na escola, sua língua natural, a libras.

O acesso tardio às formas narrativas costuma gerar, em surdos e ouvintes, dificuldades para reconhecer diferenças entre fato e ficção. Um relato mítico pode ser compreendido, inicialmente, como algo real, embora inacreditável, ou como uma história mentirosa, que não merece crédito e atenção. Essa dificuldade de separar a ficção da realidade e de deixarse envolver pelo "fantástico-maravilhoso", categorizado por Todorov (1992, p. 58) como o efeito de narrativas "que se apresentam como fantásticas e que terminam por uma aceitação do sobrenatural" é uma situação que pode ser observada, ocasionalmente, quando atores, intérpretes de vilões em novelas, são agredidos nas ruas por expectadores indignados, que não diferenciam a personagem de ficção do profissional que a interpreta.

A pouca convivência com narrativas, tanto as transmitidas de forma oral como as impressas em livros e revistas, tem relação direta com as dificuldades de leitura e compreensão de textos. Diante de turmas com um 


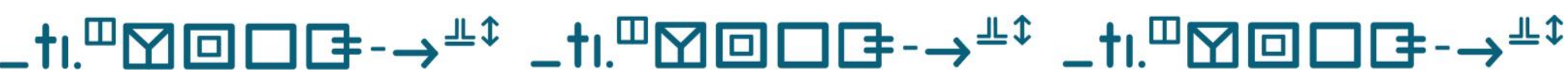

Os cantos dos Aedos em novas sensoriades e "O direito à literatura": uma adaptação da Odisseia para leitura de alunos surdos

Sueli Maria de Oliveira Regino · Goiamérico Felício Carneiro dos Santos

significativo percentual de alunos com dificuldades em ler e compreender os textos das disciplinas da área de literatura, confirmou-se a necessidade de buscar novos recursos que tornassem mais eficaz a necessária leitura desses textos. Uma das estratégias adotadas para tentar compreender melhor as dificuldades desses alunos foi o projeto Hora do Conto, iniciado em 2012, com o trabalho voluntário de professoras e intérpretes, que abraçaram o projeto ao compreender sua importância. Inicialmente, o objetivo era contar, em português e libras, narrativas de tradição oral, como as fábulas e os contos de fadas, levando para alunos adultos e adolescentes, algumas das histórias que, geralmente, são conhecidas na primeira infância.

Benefícios cognitivos e psíquicos são observados por Bruno Bettelheim (1980), em decorrência da leitura frequente de contos de tradição oral. Bettelheim (1980, p. 14) afirma que essas antigas narrativas, cuja origem se perde nos séculos, transmitem "significados manifestos e encobertos", que atuam sobre todos os níveis da psique humana: o consciente, o pré-consciente e o inconsciente. Bettelheim (1980, p. 152) descreve o inconsciente como "fonte de matéria-prima e a base sobre a qual o ego erige o edifício de nossa personalidade". Para Bettelheim (1980, p. 14), os contos de fadas tornam-se tão significativos por falarem "ao ego em germinação", encorajando o seu crescimento e, ao mesmo tempo, aliviando "pressões pré-conscientes e inconscientes". 


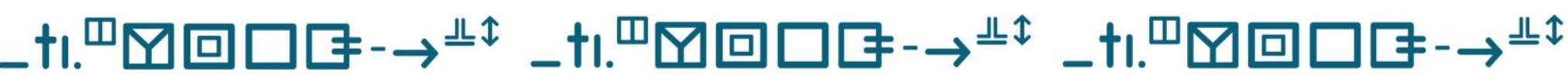

Os cantos dos Aedos em novas sensoriades e "O direito à literatura": uma adaptação da Odisseia para leitura de alunos surdos

Sueli Maria de Oliveira Regino · Goiamérico Felício Carneiro dos Santos

Nos textos de tradição oral, entre os quais estão os poemas de Homero e os contos de fadas, temas míticos se entretecem, formando seus arcabouços simbólicos. Esses temas são sinalizadores psíquicos, que conduzem a criança à descoberta de sua identidade e de suas potencialidades. Bettelheim (1980, p. 32) observa que, durante a maior parte da história dos homens sobre a terra,

[...] a vida intelectual de uma criança, fora das experiências imediatas dentro da família, dependeu das estórias míticas e religiosas e dos contos de fadas. Essa literatura tradicional alimentava a imaginação e estimulava as fantasias. Simultaneamente, como estas histórias respondiam às questões mais importantes da criança, eram um agente importante de sua socialização.

Acreditar no valor "encantatório" das histórias míticas e dos contos de tradição oral, assim como em sua eficácia para entreter, despertar curiosidade, estimular a imaginação, atuar em conflitos internos, desenvolver o intelecto e promover a socialização, foi o que moveu os criadores do projeto Hora do Conto. Foi o que os levou a apresentar alguns dos contos de fadas dos Irmãos Grimm nesses encontros semanais, criando uma tradição que perdura desde o início do projeto. Em seu percurso, a Hora do Conto vem cumprindo o objetivo de reunir alunos surdos e ouvintes para o compartilhamento de histórias lidas em português e traduzidas, simultaneamente, para a libras.

Nesses encontros, alguns dos participantes começaram a fazer vídeos das apresentações e a compartilhá-los com os colegas. Diziam que, assistindo repetidas vezes aos vídeos, 


\section{_t..}

Os cantos dos Aedos em novas sensoriades e "O direito à literatura": uma adaptação da Odisseia para leitura de alunos surdos

Sueli Maria de Oliveira Regino · Goiamérico Felício Carneiro dos Santos

aprenderiam a contar as histórias. Esses alunos trilhavam, já adultos, o mesmo caminho da criança que pede a repetição de um conto que Ihe agrada, ou ainda, da criança que lê, repetidas vezes, o mesmo livro que Ihe tocou a alma. Surgiu então a ideia de se criar uma biblioteca bilíngue, que abrigasse um acervo de livros audiovisuais. Esse novo projeto tomou forma e foi contemplado com verba do Fundo de Cultura do Estado de Goiás. Criou-se então a Bibliolibras, uma biblioteca virtual bilíngue, libras/português, que conta com um pequeno acervo de contos dos Irmãos Grimm, disponível, desde 2017, no site: www.bibliolibras.com.br.

A Fundação TV UFG também se interessou pela Hora do Conto e deu início a uma série de interprogramas (programetes) de até doze minutos de duração, reproduzindo os contos apresentados nos encontros semanais realizados na Faculdade de Letras da UFG, em Goiânia. Essas ações contribuíram para fixar os textos em forma de vídeos, possibilitando a "releitura" das histórias pelos surdos. Após dois anos apresentando contos de fadas e fábulas, surgiu a ideia de incluir a Odisseia na programação dos interprogramas. O plano do seriado seguiu o número de cantos do poema homérico, com 24 cantos e um capítulo introdutório, em que são apresentados os fatos que antecederam a Guerra de Troia, ponto de partida das ações descritas no poema.

A relevância do texto homérico e sua função didática é reconhecida desde a Antiguidade. Os poemas homéricos, antes ainda do aparecimento da escrita na Hélade, foram utilizados para educação e formação de cidadãos gregos. Não é difícil encontrar nas narrativas que constituem o arcabouço mítico da Odisseia, a descrição de situações iniciáticas, entre as quais, a mais evidente é a descida ao Hades. Os percursos 


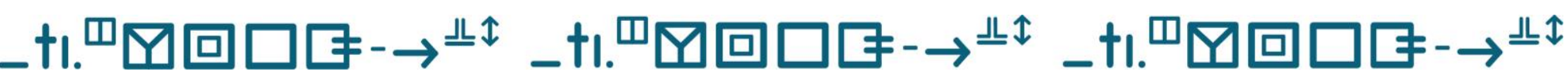

Os cantos dos Aedos em novas sensoriades e "O direito à literatura": uma adaptação da Odisseia para leitura de alunos surdos

Sueli Maria de Oliveira Regino · Goiamérico Felício Carneiro dos Santos

iniciáticos, sob a guarda de um mentor, estão presentes nas formas mais arcaicas de educação tribal e propiciam ao jovem iniciado aprendizado ético, político e social, necessário para que o jovem seja aceito como adulto em sua comunidade.

Ao descrever Odisseu, Denis Kohler (1998, p. 916) observa sua "notável plasticidade, resultante da inteligência que ele encarna". Para Kohler (1998, p. 917), o herói Odisseu é "um ser de tensões resolvidas, de contradições superpostas", que ao se ver "atirado pelos deuses e os homens de um lado para outro, entre o horror e a volúpia, o refinamento e a selvageria, quer conservar a razão, bem como a permanência do ser face à mobilidade do mundo". Os cantos da Odisseia expõem os sofrimentos e os conflitos que afligem o ser humano, obrigado a enfrentar a vida e a morte, escolhendo seu caminho entre o medo e a coragem, a civilização e a barbárie.

Ainda hoje, o milenar poema de Homero verte, fartamente, seu manancial de mitos geradores de novas produções ficcionais (contos, romances, roteiros para cinema, vídeos e seriados), e continua relevante, não apenas para a produção literária do Ocidente, como para o processo de formação de jovens leitores. A relevância dessa obra milenar, que Moraes (2012, p. 15) qualifica como "o maior tesouro literário do Ocidente", a eleva ao patamar de "bem incompressível", expressão usada por Antonio Candido (1995) para se referir às obras que compõem a herança cultural legada por nossos ancestrais, de cujos bens todos deveriam ter o direito de usufruir. E dessa totalidade, certamente, não seria imaginável, excluir os surdos. 


\section{_t..}

Os cantos dos Aedos em novas sensoriades e "O direito à literatura": uma adaptação da Odisseia para leitura de alunos surdos

Sueli Maria de Oliveira Regino · Goiamérico Felício Carneiro dos Santos

\section{A literatura como herança cultural}

Questões sobre as finalidades da literatura ocuparam a atenção de poetas e filósofos da Antiguidade e, ainda hoje, são motivo de reflexão de estudiosos dos fenômenos literários. No terceiro diálogo de A República, aparece uma breve discussão sobre a relação da arte poética com o conhecimento. Para Platão (2000), a filosofia alcança o espaço das Ideias por meio da reflexão, tornando-se assim um meio para o homem alcançar o conhecimento. A poesia, contudo, por ser representação imperfeita de um mundo que, por sua vez, não passava de cópia, também imperfeita, do espaço das Ideias, a realidade última, não poderia ser um meio de alcançar o conhecimento. Devido ao seu caráter essencialmente inexato, a poesia não estava, para Platão, no mesmo patamar da filosofia. Sob a perspectiva da ironia platônica, a ficção é mentirosa, perverte o conhecimento e deveria estar sob a censura dos filósofos da República, para que apresentasse apenas o que fosse belo e bom.

Aristóteles (2011, p. 54), contudo, na seção IX da Poética, dá à poesia a relevância que Platão parece negar, afirmando não haver "mentira" na ficção, pois "não é função do poeta realizar um relato exato dos eventos, mas sim daquilo que poderia acontecer e que é possível dentro da possibilidade ou da necessidade". Ao comparar a poesia com a história, Aristóteles (2011, p. 55) afirma que "a poesia é mais filosófica e mais séria do que a história, pois a poesia se ocupa mais do universal, ao passo que a história se restringe ao particular". Do ponto de vista ético, para Aristóteles a poesia é mais elevada do que a história e a filosofia, o que lhe concede um lugar de maior importância na aventura do conhecimento humano. 


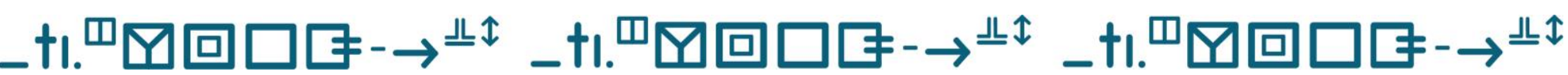

Os cantos dos Aedos em novas sensoriades e "O direito à literatura": uma adaptação da Odisseia para leitura de alunos surdos

Sueli Maria de Oliveira Regino · Goiamérico Felício Carneiro dos Santos

A partir das reflexões sobre a arte poética, desenvolvidas na Antiguidade greco-romana, conferiu-se à literatura, até meados século XVIII, "ou uma finalidade hedonista ou uma finalidade pedagógico-moralística" (AGUIAR E SILVA, 1968, 61). Essa percepção da literatura como forma de entretenimento, instrumento pedagógico ou fonte de ensinamentos morais começou a ser contestada a partir da segunda metade do século XVIII, com a contribuição de diferentes pensadores, como Baumgarten, Moritz e Kant, que trouxeram novas reflexões sobre a estética e promoveram o conceito da "arte pela arte", ou seja, uma arte criada sem qualquer outra finalidade além dela mesma.

Refreada a febre libertária que acometeu artistas e poetas até o início do século $X X$, o tema da literatura como conhecimento voltou a preocupar os teóricos. Para Ernst Cassirer (1997), a literatura, por meio de suas imagens simbólicas, revela as infinitas potencialidades da alma humana, possibilitando maior conhecimento da psique e dos espaços da vida interior, contrapondo-se assim ao conhecimento do mundo, revelado pela ciência. As observações de Cassirer são corroboradas por Aguiar e Silva (1968, p. 95), quando este afirma que, através dos tempos, a literatura

[...] tem sido o mais fecundo instrumento de análise e de compreensão do homem e das suas relações com o mundo. Sófocles, Shakespeare, Cervantes, Rousseau, Dostoievski, Kafka, etc, representam novos modos de compreender o homem e a vida e revelam verdades humanas que antes deles se desconheciam ou apenas eram pressentidas. 


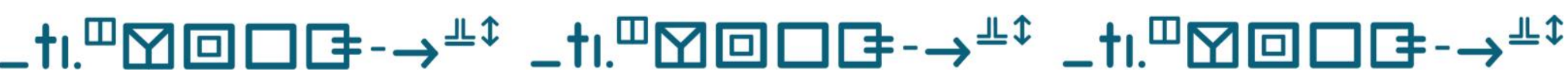

Os cantos dos Aedos em novas sensoriades e "O direito à literatura": uma adaptação da Odisseia para leitura de alunos surdos

Sueli Maria de Oliveira Regino · Goiamérico Felício Carneiro dos Santos

Em um de seus ensaios, ao responder à pergunta: "Para que serve esse bem imaterial que é a literatura?", Umberto Eco $(2011$, p.10) discorre sobre uma série de funções que a literatura assume em relação ao indivíduo e à sociedade. Segundo Eco (2011, p.10), a leitura de textos literários "mantém em exercício, antes de tudo, a língua como patrimônio coletivo" e, ao contribuir para a formação da língua de uma nação, a literatura "cria identidade e comunidade" (ECO, 2011, p.11). A prática literária, além de consolidar a língua como patrimônio coletivo, "mantém em exercício também a nossa língua individual", propiciando ao leitor "um mundo de valores que chega de e remete a livros" (ECO, 2011, p.12).

Quanto à função educativa, uma decorrência da prática literária, Eco (2011, p.20) afirma que a literatura "não se reduz à transmissão de ideias morais, boas ou más que sejam, ou à transformação do sentido do belo". As grandes obras literárias, segundo Eco (2011, p.21), educam para as "leis inexoráveis da vida", pois ensinam sobre o morrer. Ao afirmar que uma das principais funções da literatura é a "educação ao Fado e à morte", Eco confirma a atualidade e a eficácia do primitivo modelo iniciático de educação, do qual faz parte o percurso de provas, seguido de morte ritual. No decorrer de uma iniciação, o jovem iniciado, após o enfrentamento da morte, real ou simbólica, transforma-se e alcança um novo patamar em sua comunidade. O modelo iniciático de educação, frequentemente reproduzido nas obras de ficção 


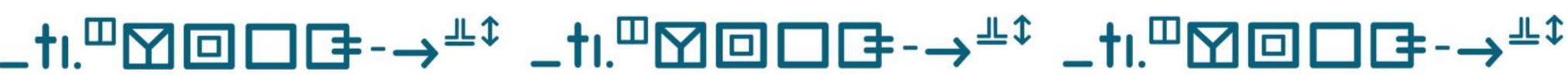

Os cantos dos Aedos em novas sensoriades e "O direito à literatura": uma adaptação da Odisseia para leitura de alunos surdos

Sueli Maria de Oliveira Regino · Goiamérico Felício Carneiro dos Santos

para jovens, proporciona uma formação verdadeiramente humanizadora, com a valorização do esforço e da coragem individual no enfrentamento das provas incontornáveis que fazem parte da vida.

Antonio Candido (1995, p. 182), ao discorrer sobre a função humanizadora da literatura, afirma compreender "humanização" como "o processo que confirma no homem aqueles traços que reputamos essenciais, como o exercício da reflexão, a aquisição do saber, a boa disposição com o próximo, o afinamento das emoções, a capacidade de penetrar nos problemas da vida", entre outras disposições e competências relacionadas à ética e à estética, responsáveis por desenvolver no leitor a sua cota de humanidade. Candido (1995) afirma que a literatura é um direito, um bem incompressível, ou seja, um daqueles bens que garantem, não só a sobrevivência física, como também a integridade espiritual de um ser. De acordo com Candido (1995, p. 188), "a literatura corresponde a uma necessidade universal que deve ser satisfeita sob pena de mutilar a personalidade, porque pelo fato de dar forma aos sentimentos e à visão do mundo, ela nos organiza, nos liberta do caos e portanto nos humaniza".

Nos parágrafos finais de seu ensaio, escrito em 1988, Candido (1995) lamentava que obras como Fausto, Dom Quixote e Os Lusíadas não fossem difundidas entre pessoas de todas as camadas sociais. Hoje, porém, a Internet tornou-se um meio de democratização da cultura, dando a todo aquele 


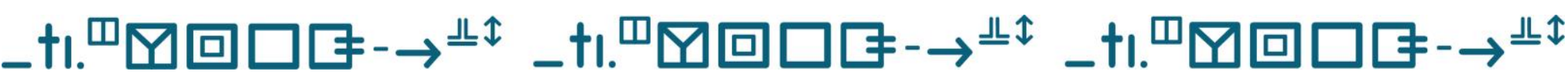

Os cantos dos Aedos em novas sensoriades e "O direito à literatura": uma adaptação da Odisseia para leitura de alunos surdos

Sueli Maria de Oliveira Regino · Goiamérico Felício Carneiro dos Santos

que possui um celular, acesso fácil a informações, museus, cursos, livros e vídeos. Dessa forma, o projeto de adaptar a Odisseia de Homero para o formato de vídeos bilíngues em português e libras, apresentando-os em forma de interprogramas na TV UFG e no Youtube, uma plataforma de compartilhamento de vídeos, poderá contribuir para que surdos e ouvintes venham a usufruir do direito de compartilhar dessa extraordinária herança cultural: o poema Odisseia de Homero.

\section{Os antecedentes e o processo de adaptação da Odisseia para libras}

O projeto de adaptação da Odisseia de Homero, no formato de roteiro para uma série de interprogramas bilíngues, foi antecedido pelo projeto Hora do Conto. Logo nos primeiros encontros, onde se contavam histórias em português e libras para alunos surdos e ouvintes, foi observada a necessidade de se adaptar os textos das histórias para uma linguagem mais coloquial, mais adequada à leitura em voz alta, que pudesse ser usada como roteiro para a interpretação simultânea em libras. Observou-se, contudo, que o rebuscado da linguagem literária de alguns tradutores dos contos de Grimm e Andersen tornava mais difícil o trabalho do intérprete. Entre os problemas mais comuns, tanto em edições impressas como nos textos disponíveis na internet, estavam os parágrafos longos; as inversões frasais; as palavras e expressões pouco conhecidas, 


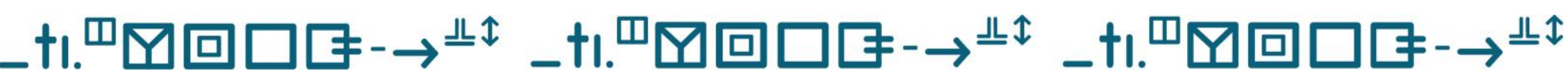

Os cantos dos Aedos em novas sensoriades e "O direito à literatura": uma adaptação da Odisseia para leitura de alunos surdos

Sueli Maria de Oliveira Regino · Goiamérico Felício Carneiro dos Santos

que acabavam por confundir intérpretes e ouvintes, ou ainda, os diálogos entre as personagens, em discurso direto, interpolados por expressões formadas com verbos discendi ou sentiendi. A essas características estilísticas, acrecentavase a extensão dos contos, que excedia, em alguns casos, o tempo disponível para a leitura. Esses entraves do texto dificultavam a interação entre o leitor, o intérprete e os participantes dos encontros.

Inicialmente, procurou-se coletâneas de contos traduzidos por autores modernos, com linguagem atual e sintaxe mais amigável, contudo, logo se percebeu que o ritmo da interpretação em libras, as especificidades da língua de sinais e de seus usuários, os receptores dessas leituras, exigiam textos escritos em linguagem mais sucinta e coloquial. Começou-se, então, a elaborar novas adaptações desses textos, ajustando a sua extensão e a linguagem, para que pudessem melhor atender aos objetivos do projeto.

$\mathrm{Na}$ redação das novas adaptações em português, buscou-se utilizar termos mais atuais, evitando expressões arcaicas ou pouco comuns. Palavras como "alguidar", "corcel" e "cântaro" foram substituídas por "tigela", "cavalo" e "pote". Quando o texto apresentava objetos desconhecidos pelos leitores modernos, como as rocas e o fuso do conto "A Bela Adormecida", o intérprete, antes de começar a narrativa, procurava expor as formas e as funções desses objetos, usando datilologia ou classificadores para apresentá-los e descrevê-los. Nos diálogos optou-se pelo uso do discurso 


\section{_t..}

Os cantos dos Aedos em novas sensoriades e "O direito à literatura": uma adaptação da Odisseia para leitura de alunos surdos

Sueli Maria de Oliveira Regino · Goiamérico Felício Carneiro dos Santos

direto, introduzido por verbos declarativos ou avaliativos, acompanhados por recursos gráficos, como os dois pontos, os travessões e as mudanças de linha. No decorrer da leitura, esses recursos facilitavam a identificação da personagem e de suas intenções, tanto pelo intérprete como pelo aluno surdo.

A proposta da Fundação Rádio e Televisão Cultural e Educativa (RTVE) - TV UFG, de levar ao ar um "programete" de 12 minutos, nos moldes dos encontros semanais da Hora do conto, levou-nos a adaptar a extensão dos textos ao tempo exigido pela produção. Com isso, o formato foi ajustado e ficou ainda mais ágil. Utilizamos as versões originais dos textos dos Irmãos Grimm, em alemão, comparando-os com traduções e adaptações em inglês, espanhol e português, disponíveis na internet e em antigas edições dos contos de Grimm em português. Dessa forma, quando surgiu a proposta para a produção de uma série baseada na Odisseia de Homero, no início de 2019, a adaptação de textos já não era exatamente uma novidade. Nesse novo projeto a obra de Homero seria apresentada no mesmo formato do interprograma $A$ hora do conto, mas em 25 episódios: um inicial, de apresentação dos mitos que antecedem a Guerra de Troia, seguido dos vinte e quatro cantos da obra original.

Estabelecer o texto que seria utilizado como roteiro para os episódios da série foi a primeira providência para dar início ao projeto. Nas diferentes traduções consultadas, em busca das que serviriam de base para a adaptação do poema 


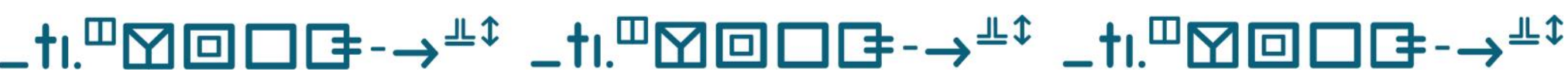

Os cantos dos Aedos em novas sensoriades e "O direito à literatura": uma adaptação da Odisseia para leitura de alunos surdos

Sueli Maria de Oliveira Regino · Goiamérico Felício Carneiro dos Santos

homérico, foram encontrados problemas um pouco mais complexos do que os presentes nas traduções dos contos dos Irmãos Grimm. Como exemplo, vejamos os versos iniciais do poema, em grego, segundo a edição da Perseus Digital Library, um site mantido pela Tufts University, que reúne textos clássicos da antiguidade greco-romana:

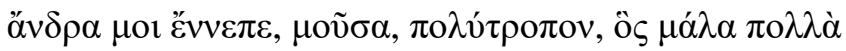

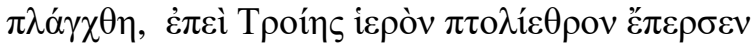

O primeiro termo que o leitor de Homero encontra ao

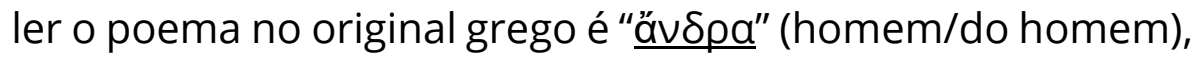
sugerindo que o tema do homem, revelado em sua miséria e grandeza, sobrepõe-se a todos os outros temas da Odisseia. Outro termo que chama a atenção do tradutor, ainda no primeiro verso do poema, é "no入útportov", com que o poeta descreve Odisseu. Separando-se "по入u'" (muitos) de "гропор" (meios, caminhos, recursos) podemos compreender o termo grego como a qualidade de alguém muito versátil, com uma mente polimorfa, rica em recursos e ardis.

Desde a Antiguidade, os caminhos da adaptação cruzam-se com os da tradução. Na prática, os dois processos se confundem e nem sempre é possível traçar com rigor os limites entre essas duas atividades. Diante de diferentes traduções do poema homérico para o português, é possível observar como as escolhas de palavras e de organização frasal alteram, de forma sutil, os significados do texto. Seguem três exemplos de traduções dos dois versos em 


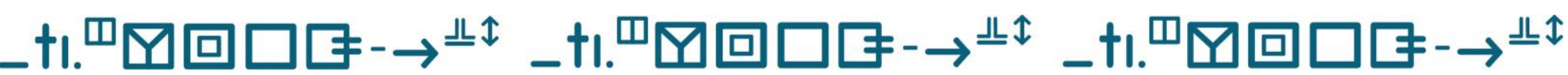

Os cantos dos Aedos em novas sensoriades e "O direito à literatura": uma adaptação da Odisseia para leitura de alunos surdos

Sueli Maria de Oliveira Regino · Goiamérico Felício Carneiro dos Santos

grego expostos acima. O primeiro é de Carlos Alberto Nunes, que formaliza os versos homéricos em 16 sílabas poéticas: "Musa, reconta-me os feitos do herói astucioso que muito peregrinou, dês que esfez as muralhas sagradas de Troia" (HOMERO, 2015, p. 29). O segundo exemplo é a tradução de Antônio Pinto de Carvalho, que utiliza a forma narrativa, sem preocupar-se com a métrica poética: “Canta para mim, ó Musa, o varão industrioso que, depois de haver saqueado a cidadela sagrada de Tróade, vagueou errante por inúmeras regiões" (HOMERO, 2002, p.15). O terceiro exemplo é da edição bilíngue traduzida, prefaciada e comentada por Donaldo Schüler: "O homem canta-me, ó Musa, o multifacetado, que muitos males padeceu, depois de arrasar Troia, cidade sacra" (HOMERO, 2011, p.13). Das três traduções, a de Schüler, um profundo conhecedor da língua

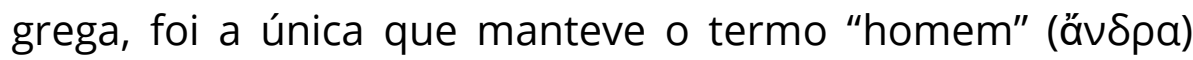
como palavra inicial do longo poema e usou "multifacetado" para traduzir "поли́тропоу", termo mais próximo ao que descreve Odisseu no texto original, valorizando a multiplicidade de aspectos do heroi.

$\mathrm{Na}$ adaptação feita para o roteiro da série de interprogramas, a primeira frase reúne os três primeiros versos, procurando combinar os critérios de economia, clareza e coloquialidade com a necessidade de acompanhar o ritmo da interpretação em libras: “Canta para mim, ó Musa, o homem de muitas astúcias, que saqueou a cidade sagrada de Troia, vagou por terras distantes, conheceu diferentes 


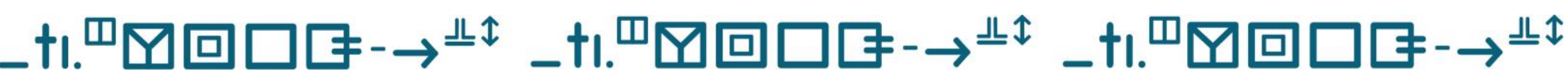

Os cantos dos Aedos em novas sensoriades e "O direito à literatura": uma adaptação da Odisseia para leitura de alunos surdos

Sueli Maria de Oliveira Regino · Goiamérico Felício Carneiro dos Santos

cidades e os costumes de muitos mortais". Esses mesmos critérios de redução textual, buscando manter a essência dos versos homéricos, foram observados ao longo de todo o trabalho de adaptação da Odisseia para o roteiro da série da TV UFG.

Cada canto do poema precisou ser limitado aos 12 minutos de leitura exigidos pela produção da TV UFG, perfazendo um total de aproximadamente 1.350 palavras por canto. No processo de redução do texto, alguns dos diálogos foram transformados em discurso indireto livre, com indicações sucintas sobre o que as personagens haviam conversado entre si. No primeiro canto, quando Atena desce do Olimpo e se apresenta no vestíbulo do palácio de Odisseu como Mentes, um guerreiro táfio, o encontro entre Telemaco e a deusa tem início no verso 113 , no momento em que o jovem príncipe percebe a presença de um estrangeiro em seu salão, e segue até o verso 319, quando a deusa se retira. $\mathrm{Na}$ adaptação, os 296 versos desse trecho do poema são apresentados em menos de 40 linhas. Schüler (2011, p. 17 e 19), assim traduz o momento da chegada de Atena ao palácio de Odisseu:

[...] Deteve-se em Ítaca, na cidade, ante o solar de Odisseu, no vestíbulo da sala. Lança de bronze em punho, tinha o aspecto de um estrangeiro, um guerreiro 105 táfio, Mentes. Estava na presença de arrogantes. Dados distraíam os pretendentes no pátio fronteiro, sentados em peles de bois que eles próprios tinham carneado. Arautos prestimosos os cercavam. Uns Ihes preparavam deliciosas porções de água e vinho, outros 110 


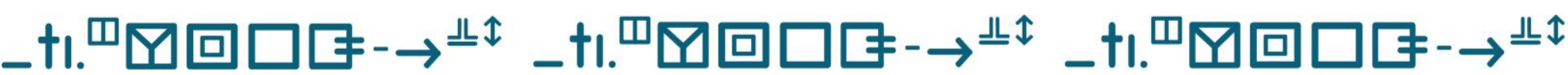

Os cantos dos Aedos em novas sensoriades e "O direito à literatura": uma adaptação da Odisseia para leitura de alunos surdos

Sueli Maria de Oliveira Regino · Goiamérico Felício Carneiro dos Santos

arrumavam as mesas. Limpavam-nas com esponjas macias e as cobriam com porções variadas de carne.

$\mathrm{Na}$ adaptação do texto de Homero para o roteiro, o mesmo trecho, que no original ocupa 10 linhas, aparece reduzido a 3 linhas e procura reter o essencial: "Ao chegar a Ítaca, assumiu a forma de Mentes, um estrangeiro, e caminhou até o palácio de Odisseu. Lá encontrou os pretendentes no pátio, se divertindo com jogos, enquanto os escravos serviam vinho e travessas de carne".

Com a redução textual, são perdidas as deliciosas imagens com as quais Homero presenteia o leitor: a lança de bronze da deusa, a arrogância dos pretendentes, as peles de bois sobre as quais jogavam dados e a movimentação dos que preparam a mesa e servem vinho aos comensais. Sempre que possível, no entanto, buscou-se preservar as imagens com maior carga simbólica, as descrições dos ambientes, embora resumidas, os epítetos, tão comuns em Homero e os diálogos mais significativos entre as personagens. Muitos trechos, originalmente em discurso direto livre, foram transformados em discurso indireto, com os acontecimentos apresentados, de forma sucinta, pela voz do narrador. Os diálogos mantidos em discurso direto tiveram suas falas abreviadas, como é possível observar neste trecho da adaptação, onde 54 versos (de 175 a 229) do Canto 1 são reduzidos a estas poucas linhas: 


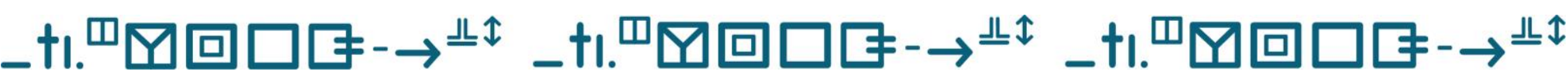

Os cantos dos Aedos em novas sensoriades e "O direito à literatura": uma adaptação da Odisseia para leitura de alunos surdos

Sueli Maria de Oliveira Regino · Goiamérico Felício Carneiro dos Santos

\begin{abstract}
Atena, a deusa dos olhos brilhantes, respondeu: "Sou Mentes, rei dos Táfios, povo amigo do remo. Meu barco está ancorado longe da cidade. Disseram que teu pai tinha voltado e por isso vim até aqui. Mas os deuses devem ter atrasado o seu retorno, pois Odisseu não morreu. Deve estar sobre o vasto mar e logo voltará a sua pátria. Tu és, de fato, filho de Odisseu? Pareces muito com ele." Com prudência, Telêmaco respondeu: "Sim, minha mãe diz que sou filho dele, mas como saber? Queria ser filho de um homem rico, para administrar os seus bem até a velhice, mas nasci do mais infeliz dos mortais". Atena, a deusa dos olhos brilhantes, replicou: "Penélope deu à luz um filho valoroso e sua casa será honrada. Mas que festa é esta? Qualquer pessoa sensata se assombraria com os abusos destes homens" (HOMERO, 2019, p.7).
\end{abstract}

Em uma adaptação que visa alcançar, prioritariamente, um público de surdos adolescentes e adultos, não se procurou escamotear realidades sociais e históricas. Os escravos são chamados de "escravos" e não de "servos" como em algumas traduções. As relações de poder, os atos de pirataria e barbárie de Odisseu, em sua viagem de retorno a Ítaca, assim como a violência de sua vingança implacável, que não poupou sequer as escravas associadas aos invasores, são apresentados sem atenuantes.

Além do original grego da Perseus Digital Library, foram utilizados para eventuais consultas os textos em grego das edições bilíngues traduzidas por Schüler (2011) e por Bérard (1972). Das traduções que serviram de parâmetro para redigir a adaptação, as que se mostraram mais úteis foram as de Donald Schüler, Victor Bérard, Luis Segala y Estalella, Antônio Pinto Carvalho e Carlos Alberto Nunes. Além dos 


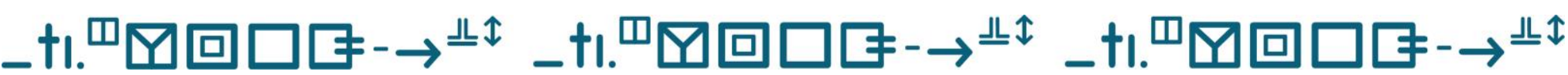

Os cantos dos Aedos em novas sensoriades e "O direito à literatura": uma adaptação da Odisseia para leitura de alunos surdos

Sueli Maria de Oliveira Regino · Goiamérico Felício Carneiro dos Santos

textos em grego e em inglês da Perseus Digital Library, foi de grande utilidade o excelente dicionário de grego/inglês disponível nesse site.

\section{Considerações finais}

Quando o saudoso professor Antonio Candido, em meados do século passado, se lamentava por serem as obras literárias tão pouco difundidas entre as camadas sociais menos favorecidas, não poderia imaginar, certamente, que em poucas décadas essas mesmas obras estariam à disposição de leitores de todas as classes sociais nas bibliotecas virtuais da Internet e ao alcance das mãos, em notebooks, tablets e celulares. Para os usuários de línguas de sinais, em todo o mundo, as plataformas de vídeos, as redes sociais e os sistemas de videochamadas foram um divisor de águas que possibilitou sua comunicação à distância, a execução de videotextos em libras e também o arquivo desses textos.

O projeto "A Odisséia de Homero: roteiro bilíngue (português/libras) para a série televisiva Hora do Conto" pretende tornar possível, a surdos e ouvintes, o acesso ao poema Odisseia de Homero, contribuindo para a divulgação e o desfrute de uma obra extraordinária, que compõe o acervo de nossa herança cultural. Essa nova realidade, proporcionada pelos meios digitais, permite aos surdos, que valorizam a língua de sinais como elemento essencial de sua cultura, não somente o usofruto da leitura de textos literários 


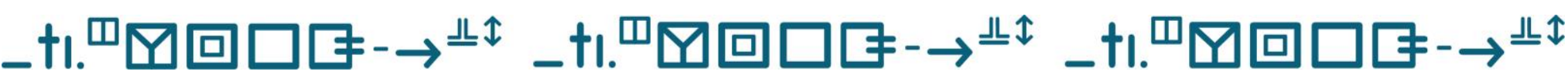

Os cantos dos Aedos em novas sensoriades e "O direito à literatura": uma adaptação da Odisseia para leitura de alunos surdos

Sueli Maria de Oliveira Regino · Goiamérico Felício Carneiro dos Santos

clássicos, como também a produção de textos de literatura surda, em libras, o que é essencial para o fortalecimento de sua identidade cultural.

Neste artigo, em que foram apresentados, de forma sucinta, os antecedentes do projeto de adaptação da Odisseia para a leitura base do intérprete de libras, discorreu-se sobre algumas das estratégias utilizadas para promover a leitura entre alunos surdos do Curso de Letras: Libras e sobre os procedimentos que nortearam o trabalho de adaptação dessa obra de Homero. A princípio, essa adaptação da Odisseia deve ser utilizada por alunos, surdos e ouvintes, que frequentam os cursos de Libras e de Tradução e Interpretação em Libras-Português na Faculdade de Letras UFG, Goiânia, mas certamente alcançará outros alunos surdos de escolas e universidades brasileiras.

A tarefa de adaptar a Odisseia de Homero para o português, na forma de um roteiro para uma série bilíngue, em libras e português, sustentou-se sobre as palavras de dois admiráveis escritores: Monteiro Lobato, para quem traduzir e adaptar textos clássicos era abrir janelas para o mundo, e Antonio Candido, que declarou ser um direito inalienável a todo ser humano o usufruto da grande herança universal legada pelas artes e pela literatura.

\section{Referências}

AGUIAR E SILVA, V. M. TEORIA DA LITERATURA. COIMBRA: LIVRARIA ALMEDINA, 1968. 


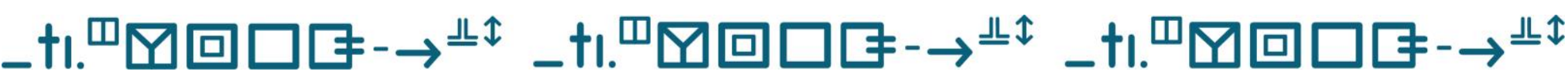

Os cantos dos Aedos em novas sensoriades e "O direito à literatura": uma adaptação da Odisseia para leitura de alunos surdos

Sueli Maria de Oliveira Regino · Goiamérico Felício Carneiro dos Santos

ARISTÓteles. poética. TRAd. edson Bini. São Paulo: Edipro, 2011.

BETTELHEIM, B. A PSICANÁLISE dOS CONTOS DE FADAS. RIO DE JANEIRO: PAZ E TERRA, 1980.

BOtTMANN, DENISE. TRAduções de MONTEIRo Lobato. 2011. DISPONÍVEL

EM:

HTTP://NAOGOSTODEPLAGIO.BLOGSPOT.COM/2011/01/TRADUCOES-

DE-MONTEIRO-

LOBATO.HTML\#: :TEXT=MONTEIRO\%20LOBATO\%20CONSIDERAVA\%20

QUE\%20A,E\%20FAL\%C3\%AANCIA\%20DE\%20SEUS\%20PROJETOS.

ACESSO EM: MAR, 2021.

CANDIDO, A. "O DIREITO À LITERATURA" IN: . VÁRIOS ESCRITOS.

SÃO PAULO: DUAS CIDADES. 1995.

CASSIRER, E. ENSAIO SOBRE O HOMEM. SÃO PAULO: MARTINS FONTES, 1997.

ECO, U. SObre A Literatura. TRAD. Eliana AGUIAR. RIO DE JANEIRO: RECORD, 2011.

HOMÈRE. L’OdYSSÉE: POÉSIE HOMÉRIQUe (TOME I, II E III). TRAD. VICTOR BÉRARD. PARIS: LES BELLES LETTRES, 1972.

homero. Odisseia. TRAD. ANTÔNIO Pinto Carvalho. São PaUlo: NOVA CULTURAL. 2002.

ODISSEIA I: TELEMAQUIA. TRAD. DONALDO SCHÜLER. PORTO

ALEGRE: L\&PM, 2011.

ODISSEIA II: REgRESSO. TRAD. DONALDO SCHÜLER. PORTO ALEGRE: L\&PM, 2011.

ODISSEIA III: ÍTACA. TRAD. DONALDO SCHÜLER. PORTO ALEGRE: L\&PM, 2011. 


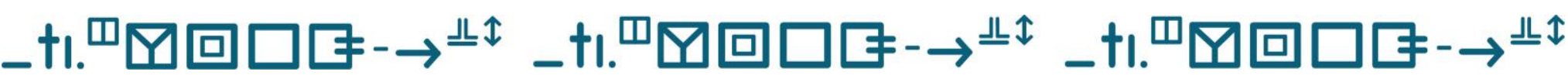

Os cantos dos Aedos em novas sensoriades e "O direito à literatura": uma adaptação da Odisseia para leitura de alunos surdos

Sueli Maria de Oliveira Regino · Goiamérico Felício Carneiro dos Santos

. Odisseia. TRad. Carlos Alberto nunes. Rio de janeiro:

NOVA FRONTEIRA. 2015.

ODISEA. TRAD. LUIS SEGALA Y ESTALELLA. MADRID: MESTAS

EDICIONES, 2015.

OdISSEIA. ADAPTAÇÃO DE MARIA DE REGINO. EBOOK KINDLE,

SÃo PAULO, $2019 . \quad$ DISPONÍVEL EM:

HTTPS://WWW.AMAZON.COM.BR/ODISSEIA-HIST\%C3\%B3RIO-

HOMERO-

EBOOK/DP/B07Z8KJXJF/REF=SR_1_4?_MK_PT_BR=\%C3\%85M\%C3

\%85\%C5\%BD\%C3\%95\%C3\%91\&DCHILD=1\&KEYWORDS=ODISSEIA

+HOMERO\&QID=1622761641\&S=DIGITAL-TEXT\&SR=1-4 ACESSO EM: ABR. 2021.

OdYSSEY. PERSEUS DigitAL LIBRARY. TUFTS UNIVERSITY.

DISPONIVEL

EM:

HTTP://WWW.PERSEUS.TUFTS.EDU/HOPPER/TEXT?DOC=PERSEUS:TEXT:19

99.01.0135 ACESSO EM: FEV 2021.

KOHLER, D. “ULISSES”. IN: BRUNEL, P. (ORG.). DICIONÁRIO DE MITOS

LITERÁRIOS. SÃo PAULO: ED. UNB/JOSÉ OLIMPO, 1998.

MORAES, A. S. DE. O OFícIO DE HOMERO. RIO DE JANEIRO: MAUAD X, 2012.

PLATÃo. Diálogos III: A RePúblicA. RIO de JANEIRO: EDIOURO, 2000.

SCHÜLER, D. "POR QUE LER A ODISSEIA?" IN: HOMERO. ODISSEIA I:

TELEMAQUiA. PORTO ALEGRE: L\&PM, 2011.

TODOROV, T. INTRODUÇÃo À LITERATURA FANTÁSTICA. TRAD. MARIA

Clara CAstello. SÃo PAulo: Ed. PeRSPECTIVA, 1992. 


\section{_tı.}

Os cantos dos Aedos em novas sensoriades e "O direito à literatura": uma adaptação da Odisseia para leitura de alunos surdos

Sueli Maria de Oliveira Regino · Goiamérico Felício Carneiro dos Santos

\section{Publisher}

UNIVERSIDADE FEDERAL DE GOIÁS. CURSOS DE LETRAS: LIBRAS E DE LETRAS: TRADUÇÃO E INTERPRETAÇÃO EM LIBRAS/PORTUGUÊS DA Faculdade de letras/ufg. Publicação no Portal de Periódicos UFG. AS IDEIAS EXPRESSADAS NESTE ARTIGO SÃO DE RESPONSABILIDADE DE SEUS AUTORES, NÃO REPRESENTANDO, NECESSARIAMENTE, A OPINIÃO DOS EDITORES OU DA UNIVERSIDADE.

\footnotetext{
' O projeto de Pós-Doutorado "A Odisséia de Homero: roteiro bilíngue (português/libras) para a série televisiva Hora do Conto\&quot; (2019), da Prof a . Dr a . Sueli Maria de Regino, foi executado sob a supervisão do Prof. Dr. Goiamérico Felício Carneiro, e está vinculado ao Programa de Pós-Graduação da Faculdade de Informação e Comunicação da Universidade Federal de Goiás.
} 